\title{
Mole manchamanteles
}

\section{Mole manchamanteles}

Elsa Nathalie Barranco Ángeles ${ }^{a}$

\begin{abstract}
:
The word mole comes from the Nahuatl mulli, sauce or stew. Term that designates an infinity of complex dishes, made with a thick sauce. It is said that in Oaxaca there is a mole for each day of the week, which is why seven moles are recognized in its great gastronomic variety. The Oaxacan moles are the yellowish, black mole, coloradito, chichilo, manchamanteles, green mole and red mole.
\end{abstract}

Keywords:

Mole, Oaxaca, chilies

\section{Resumen:}

La palabra mole proviene del náhuatl mulli, que significa salsa o guiso. Término que designa una infinidad de platillos complejos, elaborados con una salsa espesa. Se dice que, en Oaxaca existe un mole por cada día de la semana por lo que se reconocen siete moles, en su gran variedad gastronómica. Los moles oaxaqueños son el amarillito, mole negro, coloradito, chichilo, manchamanteles, mole verde y mole rojo.

Palabras Clave:

Mole, Oaxaca, chiles.

\section{Introducción}

El mole manchamanteles es un platillo de sabor dulce, elaborado con carne de cerdo mezclada con una preparación de chile ancho, clavo, pimienta, canela, cebolla, almendra, tomillo, orégano y ajo molidos. A esta salsa se le agregan trozos de frutas tropicales como piña y plátano macho, manzana y pera.

El manchamantel siempre ha sido considerado un platillo típico de los estados de Puebla y Oaxaca, de donde se supone es originario. En esas entidades existe un gran arraigo a su consumo, aunque también se acostumbra a comer en otros lugares del país.

El origen de este mole proviene de la época conventual, específicamente en la orden de las monjas clarisas. Se le atribuye esta creación a una monja que padecía sordera y que por accidente agregó otros ingredientes al mole que se le había encomendado, sin embargo está preparación fue del gusto de las demás religiosas y la receta se pasó a diferentes conventos. El nombre de este platillo se le atribuye a que era tan apreciado su sabor, que hasta manchaba los manteles.

Este mole está registrado en el recetario de Sor Juana Inés de la Cruz, en donde se incluyen recetas de platillos y postres preparados, en el convento de San Jerónimo, con ingredientes americanos y no americanos en el siglo $\mathrm{XVII}$.

El manchamantel varía en cada región donde se prepara, sin embargo, se distingue por tener sabores picantes, ahumados y dulces. 
Nombre de la Práctica

Mole manchamanteles

Insumos Requeridos para su realización

\begin{tabular}{|c|c|c|}
\hline Ingredientes & Cantidad & Unidad \\
\hline Chile ancho & 0.080 & $\mathrm{Kg}$ \\
\hline Ajo & 0.020 & $\mathrm{Kg}$ \\
\hline Cebolla & 0.040 & $\mathrm{Kg}$ \\
\hline Jitomate & 0.050 & $\mathrm{Kg}$ \\
\hline Manzana & 0.030 & $\mathrm{Kg}$ \\
\hline Pera & 0.030 & $\mathrm{Kg}$ \\
\hline Piña & 0.030 & $\mathrm{Kg}$ \\
\hline Lomo de cerdo & 1.000 & $\mathrm{Kg}$ \\
\hline $\begin{array}{c}\text { Manteca de } \\
\text { cerdo }\end{array}$ & 0.020 & $\mathrm{Kg}$ \\
\hline Azúcar & 0.005 & $\mathrm{Kg}$ \\
\hline Sal & 0.007 & $\mathrm{Kg}$ \\
\hline Pimienta & 0.003 & $\mathrm{Kg}$ \\
\hline
\end{tabular}

\section{Procedimiento}

Mise en place

1. Cocer la carne de cerdo en agua con sal, cebolla y ajo. Reservar el caldo

2. Tatemar los chiles, hidratarlos, quitar las semillas y venas.

3. Pelar y cortar la fruta en jardinera Preparación

1. Licuar la cebolla, los jitomates, el ajo y los chiles.

2. En una olla se fríe la mezcla con un poco de manteca y se le agrega el caldo donde se coció el lomo de cerdo.

3. Dejar hervir por lo menos 20 minutos a fuego medio y agregar la carne previamente rebanada, las peras ,manzanas y piña, cocinar durante 10 minutos más.

4. Servir, acompañado de arroz blanco

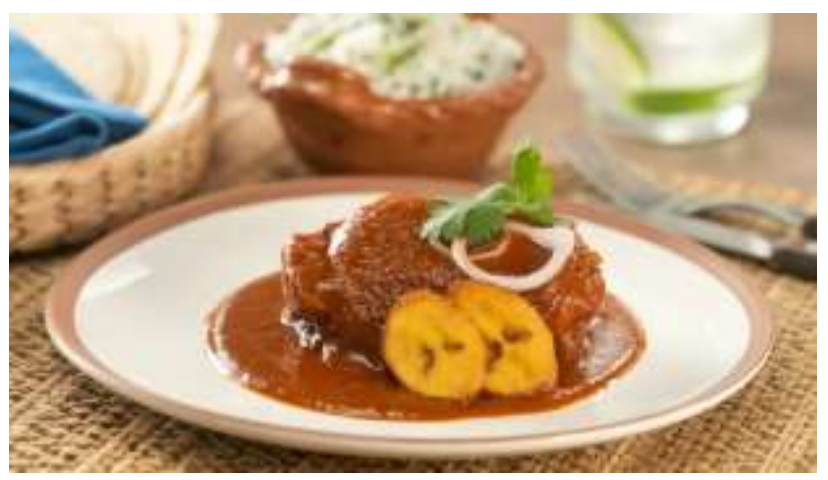

\section{Referencias}

[1] Urquiza, I. (2012). Cocina mexicana, patrimonio de la humanidad. Larousse.

[2] Zurita, R. M. (2012). Larousse, diccionario enciclopedico de la Gastronomía mexicana. Larousse

[3] 12, P. C. (2004). El mole en la ruta de los dioses. CONACULTA.

Utensilios

Olla, licuadora, cuchara. 